\title{
Article
}

\section{Atomic Force Microscopic Measurement of a Used Cylinder Liner for Prediction of Boundary Friction}

Bewsher, Stephen Richard, Leighton, M, Mohammad Pour, Mahdi, Rahnejat, Homer, Offner, Guenter and Knaus, Oliver

Available at http://clok.uclan.ac.uk/32101/

Bewsher, Stephen Richard, Leighton, M, Mohammad Pour, Mahdi, Rahnejat, Homer ORCID: 0000-0003-2257-7102, Offner, Guenter and Knaus, Oliver (2019) Atomic Force Microscopic Measurement of a Used Cylinder Liner for Prediction of Boundary Friction. Proceedings of the Institution of Mechanical Engineers, Part D: Journal of Automobile Engineering, 233 (7). pp. 1879-1889. ISSN 0954-4070

It is advisable to refer to the publisher's version if you intend to cite from the work. http://dx.doi.org/10.1177/0954407018792143

For more information about UCLan's research in this area go to

http://www.uclan.ac.uk/researchgroups/ and search for <name of research Group>.

For information about Research generally at UCLan please go to http://www.uclan.ac.uk/research/

All outputs in CLoK are protected by Intellectual Property Rights law, including Copyright law. Copyright, IPR and Moral Rights for the works on this site are retained by the individual authors and/or other copyright owners. Terms and conditions for use of this material are defined in the policies page. 
This item was submitted to Loughborough's Research Repository by the author.

Items in Figshare are protected by copyright, with all rights reserved, unless otherwise indicated.

\section{Atomic force microscopic measurement of a used cylinder liner for prediction of boundary friction}

PLEASE CITE THE PUBLISHED VERSION

https://doi.org/10.1177/0954407018792143

PUBLISHER

SAGE Publications (IMechE)

VERSION

AM (Accepted Manuscript)

\section{PUBLISHER STATEMENT}

This work is made available according to the conditions of the Creative Commons Attribution-NonCommercial 4.0 International (CC BY-NC 4.0) licence. Full details of this licence are available at: https://creativecommons.org/licenses/by-nc/4.0/

\section{LICENCE}

CC BY-NC 4.0

\section{REPOSITORY RECORD}

Bewsher, Stephen R., Michael Leighton, Mahdi Mohammadpour, Homer Rahnejat, Gunter Offner, and O. Knaus. 2019. "Atomic Force Microscopic Measurement of a Used Cylinder Liner for Prediction of Boundary Friction”. figshare. https://hdl.handle.net/2134/33956. 


\title{
Atomic Force Microscopic Measurement of a Used Cylinder Liner for Prediction of Boundary Friction
}

\author{
S.R. Bewsher ${ }^{1^{*}}$, M. Leighton ${ }^{1}$, M. Mohammadpour ${ }^{1}$, H. Rahnejat ${ }^{1}$, \\ G. Offner ${ }^{2}$ and O. Knaus² \\ ${ }^{1}$ Wolfson School of Mechanical Engineering, Loughborough University, \\ Loughborough, LE113TU, England \\ ${ }^{2} \mathrm{AVL}$ List $\mathrm{GmbH}$, Graz, Austria \\ *Corresponding author: s.r.bewsher@lboro.ac.uk
}

\begin{abstract}
Accurate simulation performs a crucial role in the design and development of new modern internal combustion engines. In the case of piston rings, simulations are used to effectively predict generated friction and power loss of proposed designs. These are consequences of viscous shear of a thin lubricant film, likewise boundary friction caused by direct interaction of piston rings with the cylinder liner/bore surface. The most commonly used model for determining boundary friction is that of Greenwood and Tripp. The model requires the pressure coefficient of boundary shear strength of asperities from the softer of the contacting surfaces as an input. This parameter needs to be measured. The paper describes the process of measurement using an Atomic Force Microscope (AFM), both for a dry surface and that wetted by the presence of a lubricant layer. For realistic results, the investigated specimen is a used, tested engine cylinder liner where boundary active lubricant additives are bonded to its surface as well as combustion products. This approach is as opposed to the previously reported works using new flat surfaces with base oil or partially formulated lubricants, and has not previously been reported in literature. The results show that for used cylinder liners, the measured boundary shear strength of asperities varies according to location along the stroke. Results are reported for the Top Dead Centre, Mid-stroke and Bottom Dead Centre locations. The measurements are subsequently used with 2D Reynolds Solution for a top compression ring-liner contact, where it is found that accurate localised predictions of generated friction and power loss can be made instead of the usual average value approach reported in literature.
\end{abstract}

\section{Keywords}

Boundary Friction, Atomic Force Microscope (AFM), Lubricant-Surface Combination, Cylinder Liner, Piston Ring Lubrication 


\section{Nomenclature}

$A$

Apparent contact area

$A_{a}$

Asperity contact area

$E^{\prime}$

Composite (reduced) Young's modulus of elasticity of contact

$b$

Ring face width

$c$

Ring crown height

$d$

Ring radial width (thickness)

Total generated contact friction

$f_{b} \quad$ Boundary friction

$f_{v}$

Viscous friction

F

Applied contact load

$F_{2}$

A statistical function

$F_{5 / 2}$

A statistical function

$F_{e}$

Ring elastic force (ring tension)

$F_{g}$

Gas force acting behind the inner rim of the ring

$g$

Ring end gap

$h$

Lubricant film thickness

$h_{m}$

Minimum lubricant film thickness

$h_{s}$

Axial profile of the ring

I

Second area moment of inertia

$k$

Ratio of contiguous surface velocities

$l$

Ring circumferential length (bore perimeter)

$\ell$

Connecting rod length

$n$

Iteration counter

$p$

Gauge pressure 


\begin{tabular}{ll}
$p_{e}$ & Elastic pressure \\
$P_{a}$ & Pressure at the ring inlet conjunction \\
$P_{c}$ & Combustion pressure \\
$P_{c a v}$ & Cavitation pressure \\
$q$ & Volumetric flow rate \\
$r$ & Crankpin radius \\
$r_{0}$ & Nominal bore radius \\
$S_{0}$ & Temperature-viscosity index \\
$t$ & Time \\
$U$ & Sliding velocity \\
$V$ & Lateral velocity (speed of side leakage flow) \\
$W$ & Total contact reaction force \\
$W_{a}$ & Load carried by the asperities \\
$W_{h}$ & Hydrodynamic reaction force \\
$x$ & Direction along the ring face-width \\
$x_{c}$ & Lubricant film rupture point \\
$y$ & Direction along the bore circumference \\
$Z$ & Pressure-viscosity index \\
\hline &
\end{tabular}

\section{Greek Symbols}

$\alpha$

Pressure-viscosity coefficient

$\alpha^{*}$

Modified pressure-viscosity coefficient

Number of asperities per unit area of contact (asperity density)

$\varphi$

Crank angle

$\eta$

Dynamic viscosity of the lubricant

$\eta_{0}$

Dynamic viscosity of the lubricant in atmospheric conditions 
Liner temperature

$\theta_{0} \quad$ Reference temperature

$\kappa$

Average asperity tip radius of curvature

K

Conformability coefficient (factor)

$\lambda$

Stribeck's oil film thickness ratio

$\rho$

Lubricant density

$\rho_{0}$

Lubricant density at atmospheric pressure

$\sigma$

\section{Introduction}

Reduction of powertrain friction, thus improving fuel efficiency is a key development aim in the automotive industry. This aim is also driven by an increasing set of global regulations and directives, tackling the harmful effects of emissions [1]. Frictional losses within various contact conjunctions have been found to contribute $20 \%$ of the overall losses within Internal Combustion (IC) engines, with the piston ring to cylinder liner conjunction representing a major portion of these losses (approximately 40-50\%) [2-4]. Therefore, accurate modelling of the piston ring assembly is important to evaluate the frictional losses for any proposed new designs. The piston ring contacts are often run in mixed or boundary regimes of lubrication as a result of high incylinder pressures during the combustion stroke and much of the compression stroke. As a result wear and high frictional losses due to the direct contact of rough surfaces or through thin lubricant films presents an issue [5, 6]. The automotive industry tackles these problems through application of hard wear-resistant surface coatings or by addition of boundary active lubricant additive packages $[7,8]$.

The operating conditions in IC engines vary considerably in normal running conditions due to the variability in loading and contact kinematics. For lubricant manufacturers the most appropriate method of friction reduction is through reduced lubricant viscosity. This is effective in reducing hydrodynamic viscous friction for 
much of the engine cycle, but can lead to reduced load carrying capacity, thus increased chance of boundary friction. Furthermore, this solution is limited by the prevalent highly loaded contact conditions in an engine, such as that in the valve train system [9]. Therefore, use of boundary active lubricant species is the solution of choice at present, as far as lubricant formulations are concerned [7].

Real engineering surfaces, such as those of piston rings and cylinder liners are rough, comprising ubiquitous asperities. The interaction of these asperities on the counterface of the surfaces in contact gives rise to boundary friction. Greenwood and Tripp [10] proposed a boundary friction model for contact of rough surfaces, where the surface roughness heights follow a Gaussian distribution. Their model is widely used for many applications, including for various engine conjunctions such as piston ring-liner contacts $[11,12]$. One of the key parameters needed in the Greenwood and Tripp model [10] is the boundary shear strength of asperities, $\varsigma$, on the softer of the two counterface surfaces. Resistance of these asperities in elastic or elastoplastic deformation through sliding motion of the counterface accounts for boundary friction. This parameter is analogous to coefficient of friction at asperity-level interactions and is often stated in reported analyses as coefficient of friction of the surface material type or through measurement by various forms of tribometry. However, the correct approach is to use Atomic Force Microscopy (AFM) in Lateral Force Mode (LFM), as described in [13-15]. These measurements should be conducted at several locations on any sample surface and with a number of measurements in each location in order to represent the average results with requisite statistical significance. However, it has been shown that in practice the surface conditions are quite localised in terms of friction as well as elasticity [16]. This is due to the localised nature of loading and kinematics as in the case of cylinder liner to piston ring conjunction. These running conditions affect the surface topography as well as formation of tribofilms, hence the elasticity of the surface as well as localised boundary friction.

The current study uses an AFM in LFM to obtain the pressure coefficient of boundary shear strength of asperities for a run-in cylinder liner at several locations. Clearly, the results depend on the service life of the liner. Therefore the liner is representative of a typical OEM mid-sized 4-cylinder engine for the majority of the service life of such an engine. The approach, however, is generic and can be applied to any IC engine cylinder system. The measured results are subsequently used in numerical analysis of tribological conditions such as prediction of generated friction and power loss. 


\section{Viscous and Boundary Friction}

The total friction, comprising its boundary and viscous shear components within a conjunction is obtained as:

$f=f_{v}+f_{b}$

Boundary friction, $f_{b}$, is obtained by calculating the proportion of the contact load carried by the opposing asperity pairs on the surface of the counterfaces, $W_{a}$, and the total area of contacting asperity peaks, $A_{a}[10]$ :

$f_{b}=\tau_{0} A_{a}+\varsigma W_{a}$

$\tau_{0}$ is the Eyring shear stress of the lubricant, which can be obtained using high shear viscometry or through use of wet LFM [17]. The Eyring shear stress occurs at the onset of lubricant non-Newtonian behaviour [18].

$W_{a}$ and $A_{a}$ are obtained as [10]:

$$
\begin{aligned}
& W_{a}=\frac{16 \sqrt{2}}{15} \pi(\zeta \kappa \sigma)^{2} \sqrt{\frac{\sigma}{\kappa}} E^{\prime} A F_{5 / 2}(\lambda) \\
& A_{a}=\pi^{2}(\zeta \kappa \sigma)^{2} \sqrt{\frac{\sigma}{\kappa}} A F_{2}(\lambda)
\end{aligned}
$$

where, the roughness parameter, $\zeta \kappa \sigma$, can be found using surface topographical measurements, in this case through use of focus variation technique using an Alicona G4 with a maximum vertical resolution of $1 \mathrm{~nm}$ and horizontal resolution of $0.174 \mu \mathrm{m}$. The ratio $\frac{\sigma}{\kappa}$ is a measure of average asperity slope [19]. The statistical functions required for the Greenwood and Tripp model, $F_{2}(\lambda)$ and $F_{5 / 2}(\lambda)$, applied here are those used for the Gaussian peak height distribution centred on $\lambda=0$ and fit from the values given by Greenwood and Tripp [10]. The curve fit polynomial functions can be stated in as:

$$
\begin{aligned}
& F_{2}(\lambda)=-0.001946 \lambda^{5}+0.02918 \lambda^{4}-0.175 \lambda^{3}+0.5274 \lambda^{2}-0.8042 \lambda+0.5 \\
& F_{5 / 2}(\lambda)=-0.003479 \lambda^{5}+0.0488 \lambda^{4}-0.2718 \lambda^{3}+0.7573 \lambda^{2}-1.067 \lambda+0.6163
\end{aligned}
$$

Viscous friction, $f_{v}$, is obtained as:

$f_{v}=\left(A-A_{a}\right) \int \frac{\tau}{L} d x$

where the lubricant shear stress is given as:

$\tau=\left|-\frac{d p}{d x} \frac{h}{2}+\frac{\eta U}{h}\right|$ 


\section{Determination of contact pressure distribution}

The conjunctional pressure distribution $p$ is obtained through combined solution of Reynolds equation, film shape and lubricant rheological state functions, using an iterative Finite Difference Method. Full details of the model and the validation against CFD [20] were reported in Bewsher et al. [21].

Reynolds equation in its 2D form for a compressible piezo-viscous lubricant can be expressed as:

$\frac{\partial}{\partial x}\left(\frac{\rho h^{3}}{6 \eta} \frac{\partial p}{\partial x}\right)+\frac{\partial}{\partial y}\left(\frac{\rho h^{3}}{6 \eta} \frac{\partial p}{\partial y}\right)=\frac{\partial(\rho U h)}{\partial x}+\frac{\partial(\rho V h)}{\partial y}+2 \frac{\partial(\rho h)}{\partial t}$

The above form of the equation includes flow in the direction of entraining motion $x$ (along the axial contact width of the ring), as well as in the side-leakage direction, $y$ (around the circumference of the ring). In the current analysis the side-leakage Couette flow is neglected as there is no circumferential sliding velocity (i.e $V=0$ ).

The lubricant density is affected by generated pressures and temperature, thus [22]:

$\rho=\rho_{0}\left(1+\frac{0.6 \times 10^{-9}\left(p-p_{0}\right)}{1+1.7 \times 10^{-9}\left(p-p_{0}\right)}\right)\left[1-0.65 \times 10^{-3}\left(\theta-\theta_{0}\right)\right]$

where $\rho_{0}$ is the lubricant density at ambient pressure and reference temperature $\theta_{0}$ and $p$ is the absolute pressure [22]. The temperature $\theta$ is that of the liner surface. It has been shown through measurements [23] that the lubricant contact temperature closely follows that of the liner.

The viscosity of lubricant also alters with pressure and temperature. The relationship provided by Roelands [24] and further developed by Houpert [25] is used:

$\eta=\eta_{0}\left(\alpha^{*} p\right)$

$\alpha^{*} p=\left[\ln \left(\eta_{0}+9.67\right)\right]\left\{\left(\frac{\theta-138}{\theta_{0}-138}\right)^{-S_{0}}\left[\left(1+\frac{p}{p_{0}}\right)^{Z}-1\right]\right\}$

The constants $Z$ and $S_{0}$ are independent of both pressure and temperature:

$Z=\frac{\alpha}{5.1 \times 10^{9}\left[\ln \left(\eta_{0}\right)+9.67\right]}$

$S_{0}=\frac{\beta\left(\theta_{0}-138\right)}{\ln \left(\eta_{0}\right)+9.67}$

The lubricant film shape is obtained as:

$h(x, t)=h_{m}(t)+h_{s}(x)$

where $h_{m}(t)$ is the minimum film thickness at any instant of time in the piston cycle and $h_{s}(x)$ is the contact face profile. 
This equation does not allow for any localised deflection of the adjoining bodies in contact or their thermo-elastic deformation. Bolander et al [12] and Mishra et al [26] show that the generated lubricant pressures in ring-liner conjunction are insufficient to cause any localised contact deflection. In practice, the rings can undergo modal behaviour as in $[27,28]$. This is not taken into account in the current analysis.

Assuming a parabolic ring contact face profile, then:

$h_{S}(x)=\frac{c(x-b / 2)^{2}}{(b / 2)^{2}}$

The generated pressures in the conjunction oppose the applied forces onto the ring, pushing it radially outwards, towards the surface of the liner. These outward radial forces are the elastic force due to ring tension and combustion gas force acting on the compression ring:

$F=F_{e}+F_{g}$

The gas force, $F_{g}$ acts behind the inner rim of the ring, where the combustion pressure, $p_{g}$, is obtained from the combustion pressure curve from measured engine data. Thus:

$F_{g}=p_{g} b l$

Assuming the ring has a rectangular cross-section, the elastic ring tension force, $F_{e}$, is found as a function of the elastic pressure, $p_{e}$ as:

$F_{e}=p_{e} b l$

$p_{e}=\frac{g E I}{3 \pi b r_{0}^{4}}$

$I=\frac{1}{12} b d^{3}$

Fully flooded inlet conditions are assumed in most reported hydrodynamic analyses. This assumes that a sufficient volume of lubricant would be available at the inlet of each ring in the ring-pack. Hence, the edge of the ring is taken as the position of the inlet meniscus. Thus, the boundary condition at the inlet is:

$p_{x=-b / 2}=P_{a}$

$P_{a}$ is assumed to be the crank-case pressure during the piston down stroke, and the combustion chamber pressure during the upstroke. The outlet boundary condition used in this analysis is Reynolds (or Swift-Steiber) [29, 30], determining the location of the lubricant film rupture along the entraining $x$-direction of the contact. It is assumed that cavities form fingers with lubricant flows between them, although the effect at the cavity-fluid interface is ignored. Arcoumanis et al. [31] conducted an experiment, which showed that predictions using the Swift-Steiber boundary 
conditions matched the experimental observations for the most of the engine stroke. Accordingly, the exit boundary conditions become:

$\left\{\begin{array}{l}p_{x=x_{c}}=P_{c a v} \\ \left.\frac{\partial p}{\partial x}\right|_{x=x_{c}}=0\end{array}\right.$

In the current analysis the cavitation pressure, $P_{\text {cav }}$, is considered to be the atmospheric pressure at the lubricant film rupture boundary: $x=x_{c}$. The forces acting upon the ring are summarised in Figure 1.

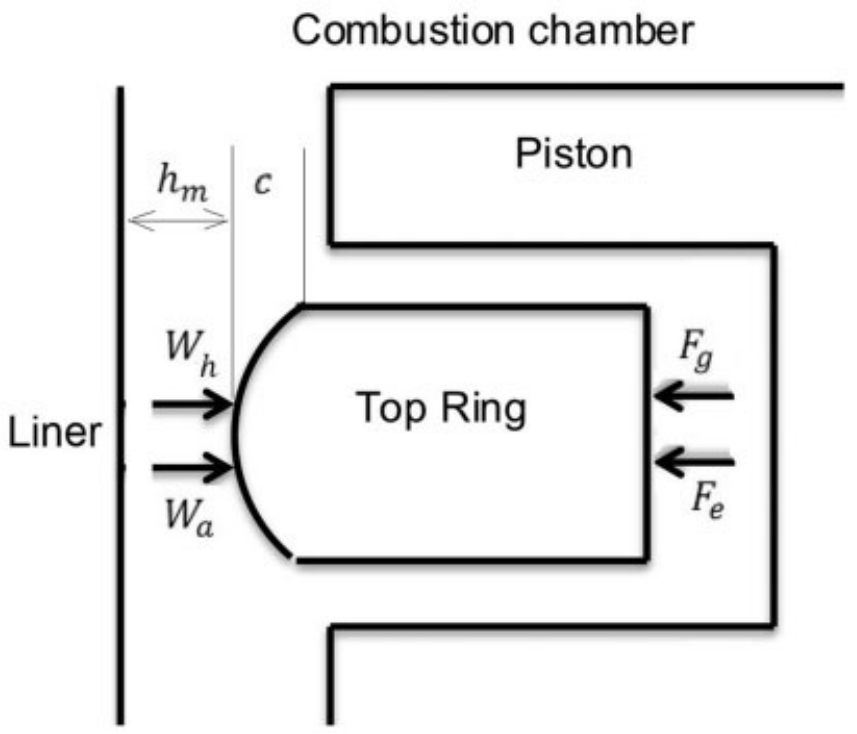

Figure 1: Forces acting radially within the piston ring - liner conjunction

\section{Cylinder Liner and Lubricant Specification}

The current study focuses on the measurement of $\varsigma$, taking into account a real world component and a fully formulated lubricant. To carry out wet AFM in lateral force mode, Mobil Super 3000 5W-20 lubricant is used which is the same as that employed throughout the fired engine testing life time.

Three different regions of the cylinder liner were identified for the purpose of measurements. The value of $\zeta$ is measured for each region as it is anticipated that each region of the liner has been subjected to its localised conditions, arising from bonding/adherence of various lubricant additives, mainly anti-wear and friction modifiers. These lubricant species are activated through application of pressure, shear and temperature. Therefore, it is assumed that a constant average value of $\zeta$, usually assumed, would not be representative of the in situ conditions [16].

Table 1 lists the material properties of the liner. The tested zones on the sample are shown in Figure 3 and are explained in detail below. 

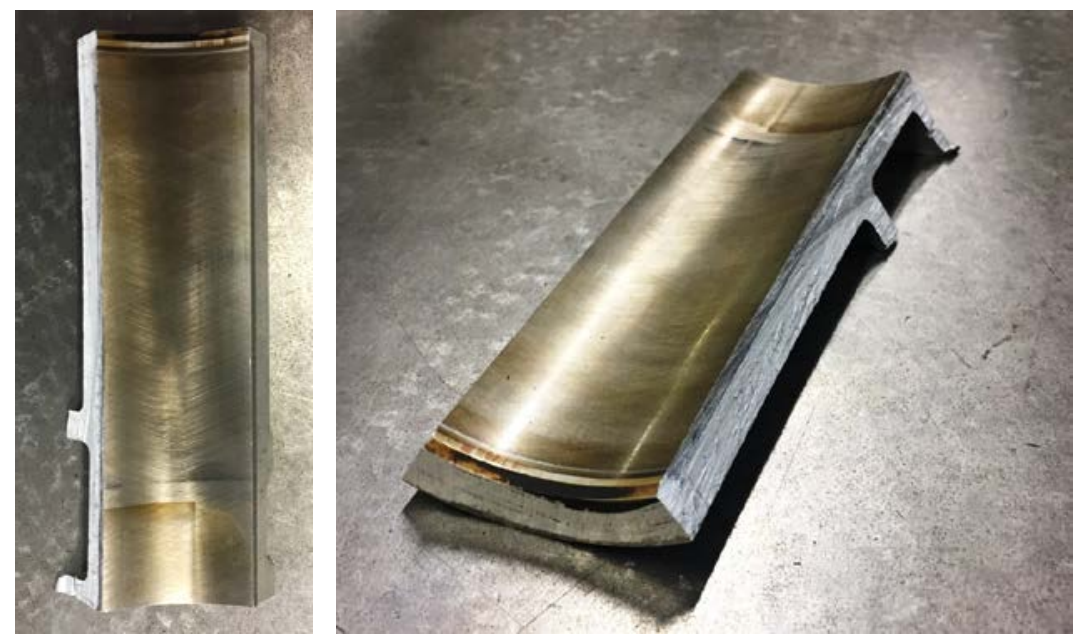

Figure 2: Cut-out Section of the Measured Cylinder Liner

Table 1: Cylinder Liner Material Properties

\begin{tabular}{|l|c|c|}
\hline Property & Value & Unit \\
\hline Elastic modulus & 120 & $\mathrm{GPa}$ \\
\hline Poisson's ratio & 0.28 & - \\
\hline Hardness (H) & 2325 & $\mathrm{MPa}$ \\
\hline Engine testing condition & 105000 & Miles \\
\hline
\end{tabular}

Top Dead Centre (TDC): This area corresponds to the region in which the top compression and scraper rings reside when the piston is at the TDC. This region is subjected to lubricant starvation owing to cessation of entraining motion because of piston reversal.

Mid-Span: This region represents the position of the top compression and scraper rings when the piston is at mid-stroke, with highest sliding velocity (viscous shear).

Bottom Dead Centre (BDC): This area corresponds to the region in which the top compression and scraper rings reside when the piston is at the BDC. This region is subjected to least contact pressure and momentary cessation of lubricant entrainment due to piston reversal. 


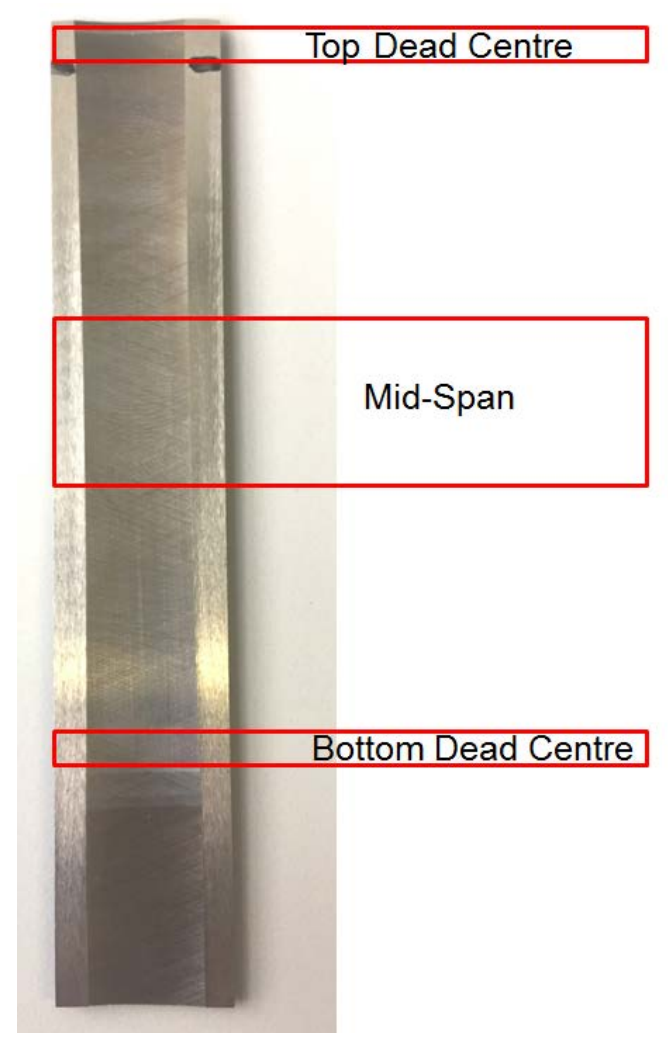

Figure 3: Identification of different zones within the Cylinder Liner

\section{Experimental Procedure - Atomic Force Microscopy}

In order to accurately predict boundary friction within a contact, the coefficient of boundary shear strength of asperity interactions, $\varsigma$, is required as shown in Equation (2). The value of $\varsigma$ is obtained using an AFM, operating in LFM [14, 15, 32, 33]. The parameters used for the LFM carried out in the current study are listed in Table 2. LFM requires an AFM probe to be calibrated for frictional measurements [32, 34]. A Bruker DNP-10 probe with 4 tips is used for this analysis. Each tip is located on a separate triangular armed cantilever. In this analysis a tip with a spring constant of $0.350 \mathrm{Nm}^{-1}$ and a nominal tip radius of $20 \mathrm{~nm}$ has been used. The full specification for the tip used is provided in Table 3. 


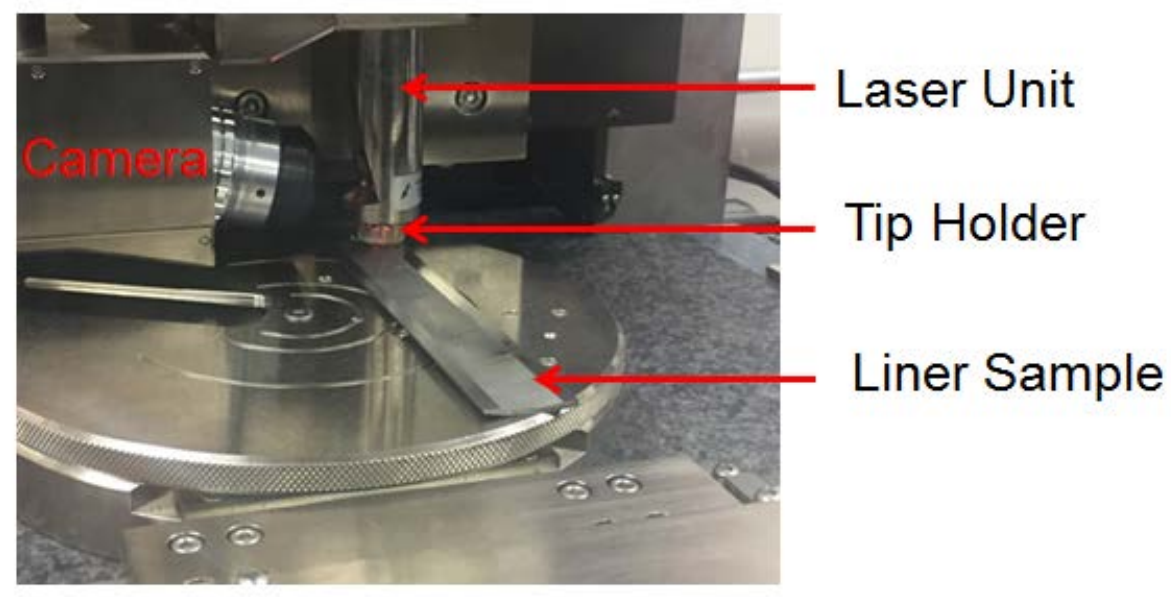

Figure 4: Cylinder Liner Sample undergoing AFM Measurement in Dry Conditions Table 2: AFM Settings for LFM

\begin{tabular}{|l|c|}
\hline Parameter & Value \\
\hline Scan size & $4 \mu \mathrm{m}$ \\
\hline Scan rate & $2 \mathrm{~Hz}$ \\
\hline Samples/line & 1024 \\
\hline Aspect ratio & 4 \\
\hline Scan angle (Friction) & $90^{\circ}$ \\
\hline
\end{tabular}

Table 3: Specification of the AFM Probe

\begin{tabular}{|l|c|}
\hline Model & DNP-10 \\
\hline Material & Non-Conductive Silicon Nitride \\
\hline $\mathrm{K}$ & $0.350 \mathrm{Nm}^{-1}$ \\
\hline Tip radius & $20 \mathrm{~nm}$ \\
\hline
\end{tabular}

To calibrate the AFM tip a silicon wafer of known topographical parameters and frictional properties $\left(s_{s i}=0.19 \pm 0.1\right)$ is used [35]. The Trace-Minus-Retrace (TMR) values are first obtained as a result of the measured lateral forces, whereby a plot of friction (in volts) versus applied load (in volts) is obtained. The applied load is varied by changing the deflection set point relative to the initial vertical deflection signal. The relationship between applied load in Volts and applied load in Newtons can be determined by taking a force curve, in which the fixed arm of the cantilever is lower and raised by known amounts and the measured cantilever deflection is determined by application of the cantilever spring constant. Using this information for a tip of 
known stiffness it is then possible to find the value of $\psi$ for the AFM and tip as outlined by Buenviaje et al [34] as the blind calibration method.

The same calibration routine is carried out for both wet and dry measurements. In order to add the lubricant a syringe is used to create a meniscus which surrounds the tip holder, but at a distance sufficiently far away from the tip itself to ensure that meniscus forces are negligible.

\section{Results and Discussion}

\section{Determining the Coefficient of Boundary Shear Strength, $\varsigma$}

Figure 5 shows the measured contact friction data under dry condition for the liner specimen in the defined regions of the TDC, BDC and at piston mid-span. The gradient of each line represents the value of $s$ for the measured region. Figure 6 shows the equivalent measurement under lubricated (wet) condition.

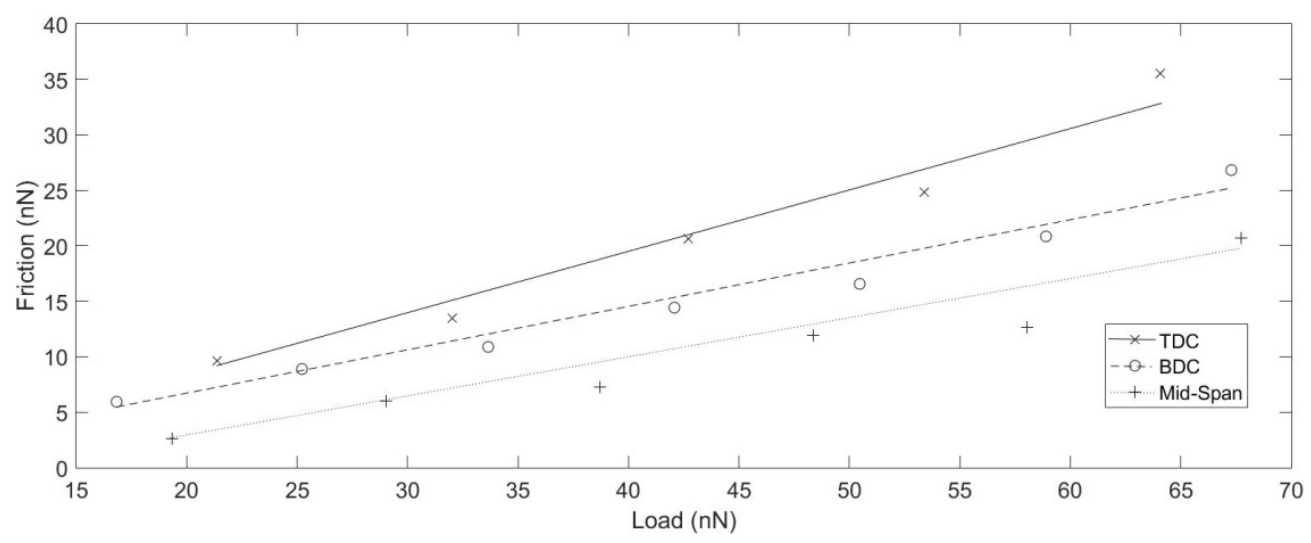

Figure 5: Measured Dry Contact LFM Results

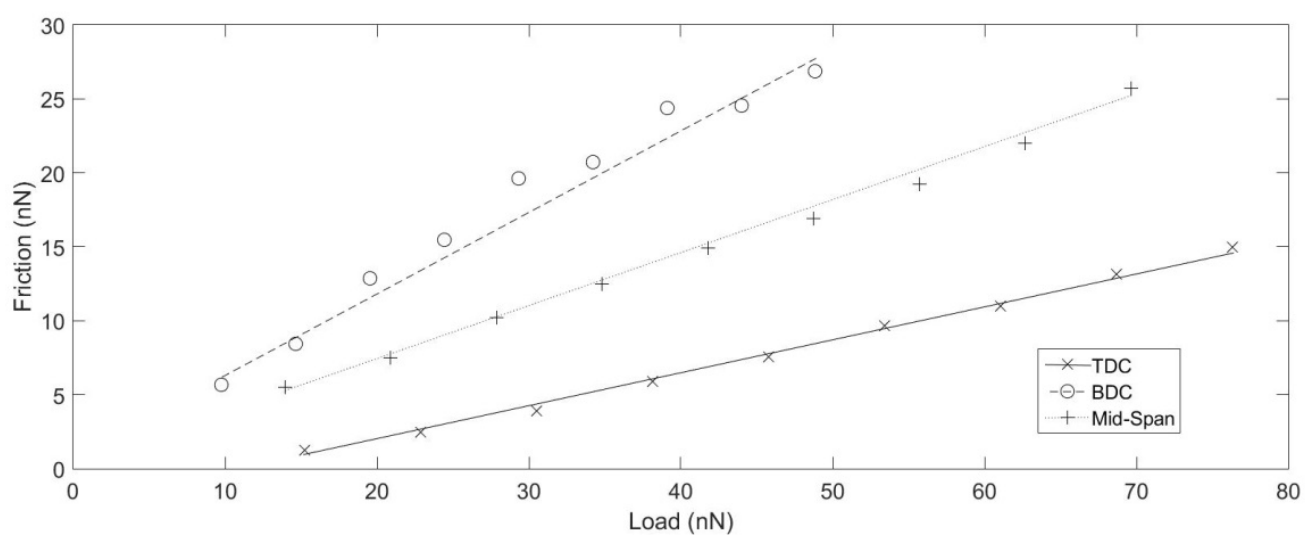

Figure 6: Measured Wet Contact LFM Results 
Table 4 is a summary of the measured LFM results under dry and wet contact conditions. The results have been taken as an average of 5 data points within each region.

Table 4: Measured LFM Results

\begin{tabular}{|c|c|c|c|}
\hline Zone & TDC & BDC & $\begin{array}{c}\text { Mid- } \\
\text { span }\end{array}$ \\
\hline$\varsigma$ (dry) & 0.591 & 0.487 & 0.347 \\
\hline$\varsigma$ (wet) & 0.229 & 0.551 & 0.351 \\
\hline
\end{tabular}

The results are taken from scans of the surface measuring $1024 \times 256$ data points across an area of $4 x 1 \mu \mathrm{m}^{2}$. It is interesting to observe how the coefficient of boundary shear strength of asperities varies for each of the defined zones for both wet and dry contacts. One possibility for the increase in the value of $s$ under dry contact condition in the TDC and BDC zones is due to increased deposits of anti-wear additive ZDDP, particularly under boundary regime of lubrication, which is prevalent at piston reversals. These results also show the importance of applying a variable zonedependent value for $s$ in predictive analyses.

\section{Model Validation}

The 2D Reynolds solver was validated using an established CFD model presented by Shahmohamadi et al $[20,36]$. This CFD model uses a 3D solution of the NavierStokes equation and is validated against experimental results, but is costly in terms of computation. The inputs for the model are shown in Tables 5, 6 and 7, using the combustion curve from Shahmohamadi et al. [36] running at an operational engine speed of $1500 \mathrm{rpm}$. The comparison of results for minimum film thickness are presented in Figure 7, showing a maximum deviation of $10 \%$ between results. Thus, it can be concluded that the model used in this paper has good agreement with that of a more detailed, computationally expensive CFD model.

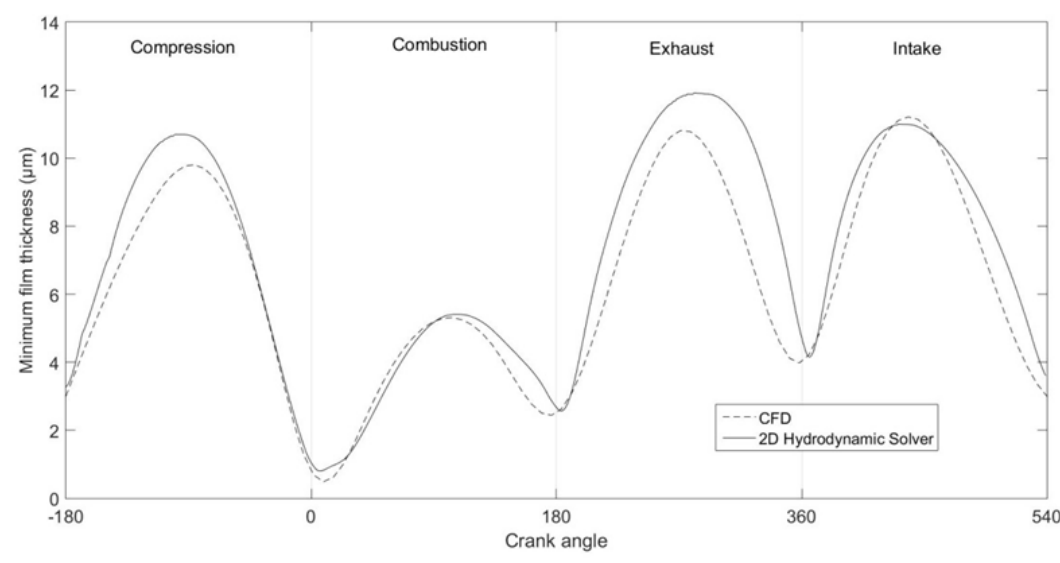

Figure 7: Minimum Film Thickness Validation Against CFD (Shahmohamadi et al. [20, 36] 


\section{Simulation Results from Top Compression Ring Contact}

The engine data is listed in Table 5. The lubricant rheological data, as well as surface parameters and material properties are listed in Tables 6 and 7 . The engine speed used in the current study is $1500 \mathrm{rpm}$, corresponding to $35 \mathrm{~km} / \mathrm{h}$ on the New European Drive Cycle (NEDC) with the vehicle driven in $3^{\text {rd }}$ gear, with an output torque of $52.03 \mathrm{Nm}$. Figures 8 and 9 show the measured in-cylinder combustion pressure and the liner temperature for an engine cycle respectively.

Table 5: Engine Data

\begin{tabular}{lcc}
\hline Parameters & Values & Units \\
\hline Torque & 52.03 & $\mathrm{Nm}$ \\
No. of cylinders & 4 & - \\
Engine type & Gasoline SI & - \\
Crank-pin radius, $r$ & 39.75 & $\mathrm{~mm}$ \\
Connecting rod length, $l$ & 138.1 & $\mathrm{~mm}$ \\
Bore nominal radius, $r_{0}$ & 44.52 & $\mathrm{~mm}$ \\
Ring crown height, $c$ & 10 & $\mu \mathrm{m}$ \\
Ring axial face-width, $b$ & 1.15 & $\mathrm{~mm}$ \\
Ring radial width, $d$ & 3.5 & $\mathrm{~mm}$ \\
Ring free end-gap, $g$ & 10.5 & $\mathrm{~mm}$ \\
\hline
\end{tabular}

Table 6: Lubricant Properties at Atmospheric Pressure and $40^{\circ} \mathrm{C}$

\begin{tabular}{lcc}
\hline Parameters & Values & Units \\
\hline Lubricant viscosity, $\eta_{0}$ & 0.05 & $\mathrm{~kg} / \mathrm{ms}$ \\
Lubricant density, $\rho_{0}$ & 833 & $\mathrm{~kg} / \mathrm{m}^{3}$ \\
$\alpha_{0}$ & $1 \times 10^{-8}$ & $\mathrm{~m}^{2} / \mathrm{N}$ \\
Lubricant Eyring shear & $2.17[17]$ & $\mathrm{MPa}$ \\
stress, $\tau_{0}$ & & \\
\hline
\end{tabular}

Table 7: Material Properties and Surface Topographical Parameters

\begin{tabular}{lcc}
\hline Parameters & Values & Units \\
\hline $\begin{array}{l}\text { Liner material } \\
\text { Modulus of elasticity of the }\end{array}$ & Grey cast iron & - \\
$\begin{array}{l}\text { liner material } \\
\text { Poisson's ratio for the liner }\end{array}$ & 92.3 & $\mathrm{GPa}$ \\
$\begin{array}{l}\text { material } \\
\begin{array}{l}\text { Density for the liner } \\
\text { material }\end{array}\end{array}$ & 0.211 & - \\
$\begin{array}{l}\text { Ring material } \\
\text { Modulus of elasticity of the } \\
\text { ring material }\end{array}$ & 7200 & $\mathrm{~kg} / \mathrm{m}^{3}$ \\
$\begin{array}{l}\text { Poisson's ratio for the ring } \\
\text { material }\end{array}$ & Steel SAE 9254 & - \\
$\begin{array}{l}\text { Roughness parameter } \\
(\zeta \kappa \sigma)\end{array}$ & 203 & $\mathrm{GPa}$ \\
\hline
\end{tabular}




\begin{tabular}{lcc}
\hline $\begin{array}{l}\text { Measure of asperity } \\
\text { gradient }\left(\frac{\sigma}{\kappa}\right)\end{array}$ & 0.001 & - \\
Density for ring material & 7700 & $\mathrm{~kg} / \mathrm{m}^{3}$ \\
\hline
\end{tabular}

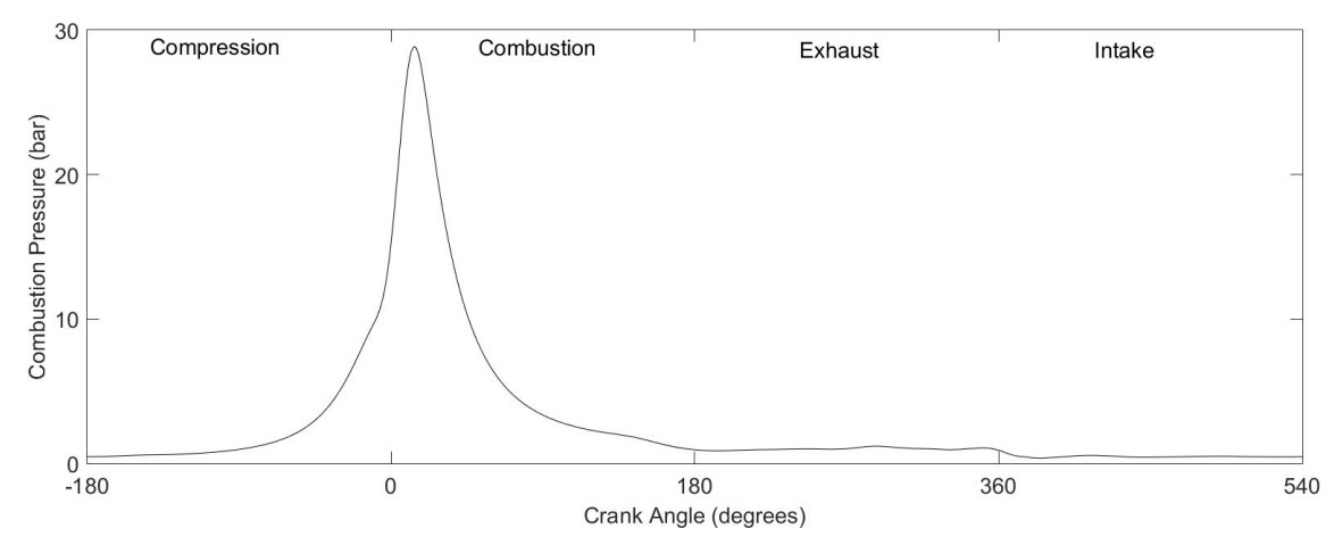

Figure 8: Combustion Pressure

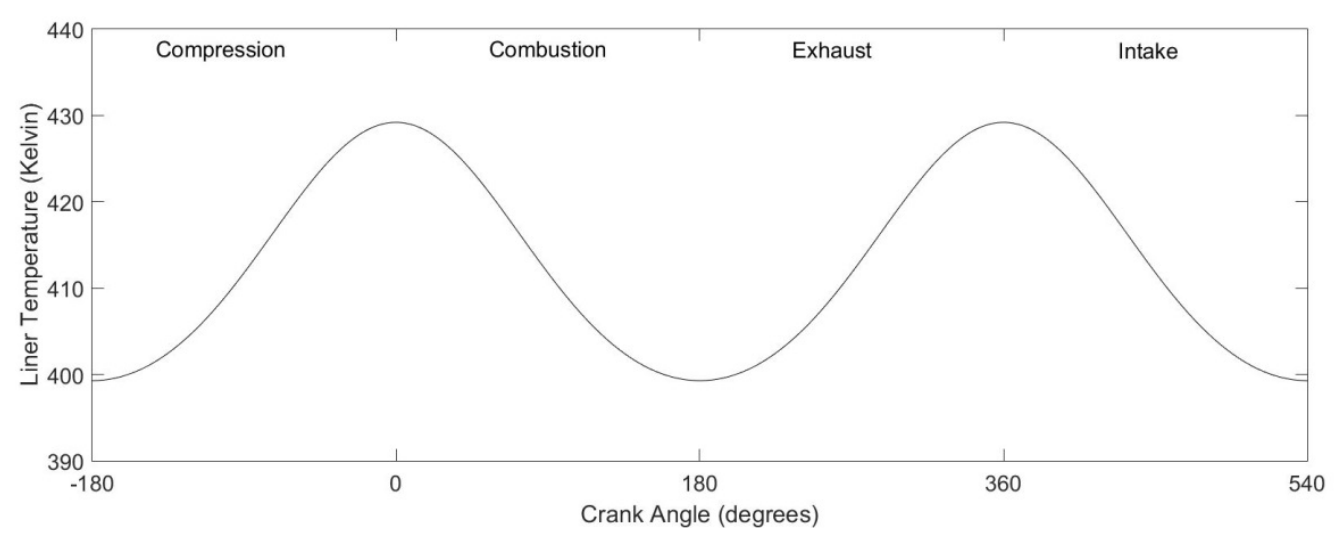

Figure 9: Measured Liner Temperature

The experimentally obtained boundary shear strength of asperities is used in the analysis for prediction of friction and power loss. The numerical model is run for a single average coefficient of friction for the wet results $(s=0.377)$ as well as with the variable coefficient of boundary shear strength of asperities values listed in Table 4 as a step function between the different zones. This is in order to ascertain the degree of inaccuracy when an average value is adopted.

Figure 10 shows the predicted minimum lubricant film thickness for the ring-liner conjunction for a complete 4-stroke cycle. The figure shows reduced film thickness in transition from compression to combustion (power) stroke. The film thickness ratio of $\lambda=\frac{h}{\sigma}$ falling below the value 3 indicates some direct interaction of counterface surface asperities. This occurs at or in the vicinity of piston reversals at the TDC (crank angle of $0^{\circ}$ ) and at the BDC (crank angle of $180^{\circ}$ ). Figure 11 shows the 
corresponding cyclic total friction in the top compression ring-to-liner conjunction. It can be seen that the results with an averaged value of $\varsigma$ exhibit much higher peak values in the combustion stroke, particularly from the TDC to the detonation point (peak combustion pressure) and in its immediate vicinity. Higher temperatures in this part of the engine cycle give rise to the activation of additives such as ZDDP which tend to increase friction as noted in many tribometric experiments [37, 38]. It is clear that increased value of $s$ in a localised manner is due to presence of formed tribofilms of higher friction characteristics. The results in Figure 11 are also comparable to the experimental findings of Gore et al. [39] using a floating liner method, it was shown that during the combustion stroke boundary interactions are dominant.

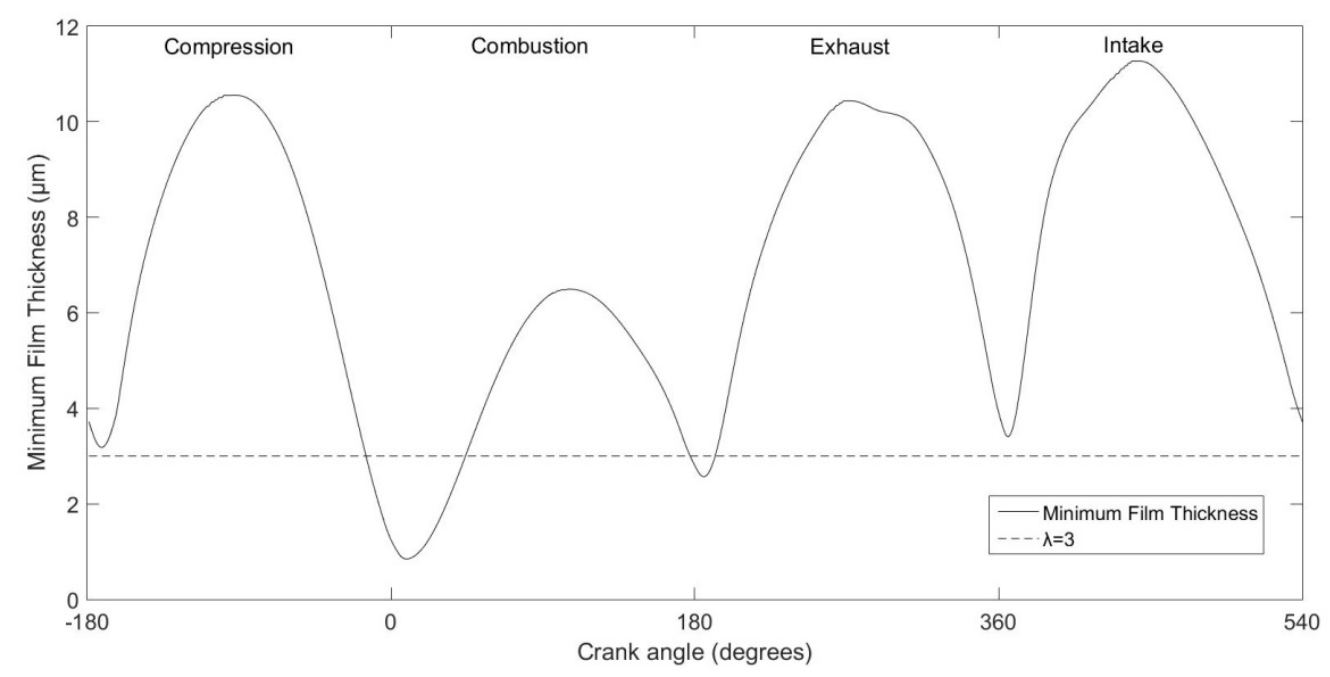

Figure 10: Cyclic Variation of Minimum Film Thickness

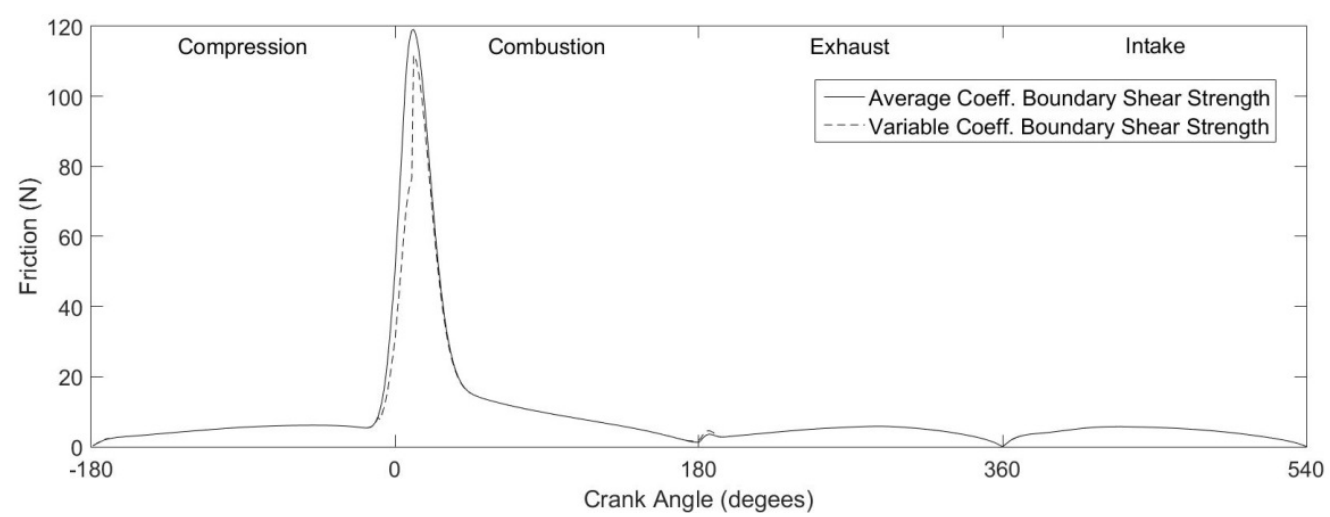

Figure 11: Cyclic Total Friction

The Power loss variation is shown in Figure 12. This is computed as a multiplication of the friction and sliding velocity.

It can be seen that the Power Loss due to a variable coefficient of boundary shear strength for the case studied is reduced from that of an average value within the 
combustion stroke. An interesting point to note is that anti-wear tribofilms, whilst desired to mitigate wear have the drawback of reduced fuel efficiency on the account of increased generated friction and power loss.

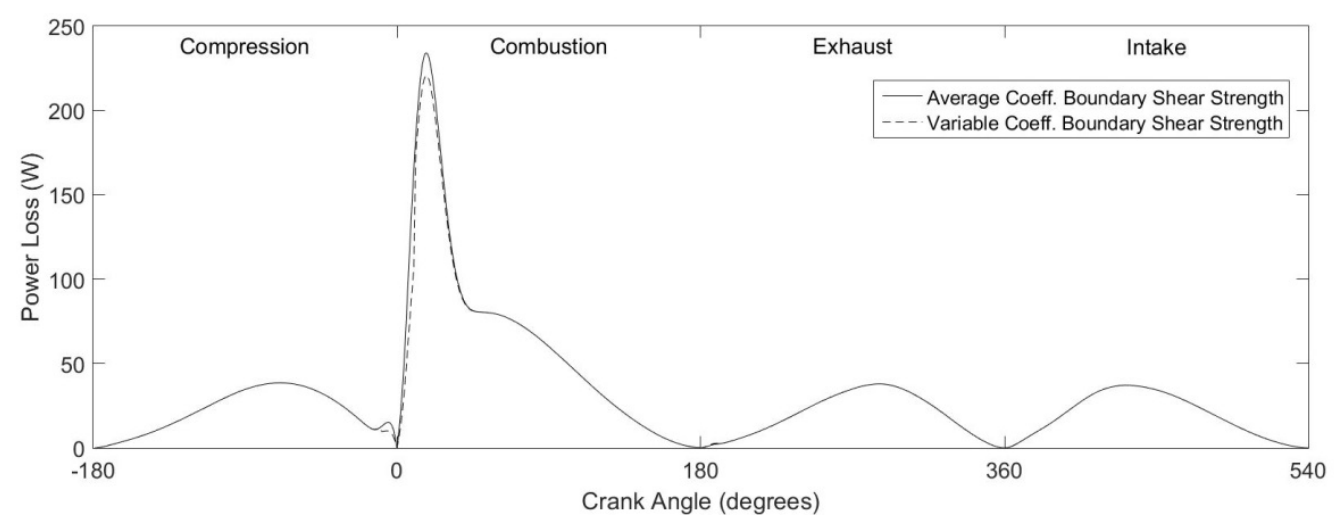

Figure 12: Power Loss

\section{Concluding Remarks}

Reported analyses have used a single averaged value for $\varsigma$. This can lead to inaccurate prediction of contact friction as the value of $s$ is localised, often depending on the formed tribofilms of boundary active lubricant additives under mixed or boundary regimes of lubrication. Precise measurement of $s$ values as a localised parameter leads to more representative predictions. It also enables the understanding of localised conditions, where supplementary palliative measures may be undertaken to mitigate against any increased friction, for example as the result of the formation of high friction tribofilms. These palliative measures can include addition of suitable friction modifier species in the lubricant formulation, coating of surfaces or progressively favour texturing of contacting surfaces.

The combined precision measurements and numerical analysis has also shown the importance of using test specimen from real system components run under representative operating conditions.

\section{Acknowledgements}

The authors are grateful for the financial and technical support received from the Engineering and Physical Sciences Research Council (EPSRC) and AVL List throughout this study.

\section{References}

[1]- King, J., "The King Review of low-carbon cars: Part I: the potential for CO2 reduction", Office of Public Sector Information, HM Treasury, HMSO, UK, 2007. 
[2]- Tung, S.C. and McMillan, M.L., "Automotive tribology overview of current advances and challenges for the future", Tribology Int., 2004, 37, pp. 517-536.

[3]- Fitzsimons, B., "Introduction to the importance of fuel efficiency and role of the Encyclopaedic research project", In IMechE Seminar: A Drive for fuel efficiency, Loughborough, 2011.

[4]- Holmberg, K., Andersson, P. and Erdemir, A., "Global energy consumption due to friction in passenger cars", Tribology International, 2012, 47, pp. 221234.

[5]- Briscoe, B.J., Scruton, B. and Willis, F.R., "The shear strength of thin lubricant films", Proc. Roy. Soc. London, A-333, 1973, pp. 99-114.

[6]- Wong, V.W. and Hoult, D.P., "Experimental survey of lubricant-film characteristics and oil consumption in a small diesel engine", SAE Technical Paper 932789, 1989.

[7]- Neville, A., Morina, A., Haque, T. and Voong, M., "Compatibility between tribological surfaces and lubricant additives-how friction and wear reduction can be controlled by surface/lube synergies", Tribology International, 2007, 40(10), pp. 1680-1695.

[8]- Howell-Smith, S., Rahnejat, H., King, P.D. and Dowson, D., "Reducing incylinder parasitic losses through surface modification and coating", Proc. IMechE, Part D: J. Automobile Engineering, 2014, 228(4), pp. 391-402.

[9]- Kushwaha, M. and Rahnejat, H., "Transient elastohydrodynamic lubrication of finite line conjunction of cam to follower concentrated contact", J. Phys., D: Applied Physics 35(21), 2002: 2872.

[10]- Greenwood, J.A. and Tripp, J.H., "The contact of two nominally flat rough surfaces", Proc. IMechE, 1970-1971, 185, pp. 625-634.

[11]- Akalin, O. and Newaz, G.M., "Piston ring-cylinder bore friction modelling in mixed lubrication regime: Part I - Analytical Results", Trans. ASME, J. Tribology, 1999, 123 (1), pp. 211-218.

[12]- Bolander, N. W., Steenwyk, B. D., Sadeghi, F., and Gerber, G. R., "Lubrication regime transitions at the piston ring-cylinder liner interface", Proc. IMechE, Part J: J. Engineering Tribology, 2005, 129, pp. 19-31.

[13]- Meyer, G. and Amer, N.M., "Simultaneous measurement of lateral and normal forces with an optical beam deflection atomic force microscope", Appl. Phys. Letts., 57, 1990, pp. 2089-2091. 
[14]- Bhushan, B. and Marti, O., "Scanning probe microscopy-principle of operation, instrumentation, and probes", In Springer Handbook of Nanotechnology, Springer Berlin Heidelberg, 2004, pp. 325-369 .

[15]- Chong, W.W.F., Teodorescu, M. and Rahnejat, H., "Nanoscale elastoplastic adhesion of wet asperities", Proc. IMechE, Part J: J. Engineering Tribology, 2013, 227(9), pp. 996-1010.

[16]- Scherer, V., Bhushan, B., Rabe, U. and Arnold, W., "Local elasticity and lubrication measurements using atomic force and friction force microscopy at ultrasonic frequencies", IEEE Trans. on Magnetics, 1997, 33(5), 4077-4079.

[17]- Leighton, M., Nicholls, T., De la Cruz, M., Rahmani, R. and Rahnejat, H., "Combined lubricant-surface system perspective: Multi-scale numericalexperimental investigation", Proc. IMechE, Part J: J. Engineering Tribology, 2017, 231(7), pp. 910-924.

[18]- Eyring, H., "Viscosity, plasticity, and diffusion as examples of absolute reaction rates", J. chemical physics, 1936, 4(4), pp. 283-291.

[19]- Gohar, R. and Rahnejat, H., "Fundamentals of Tribology", Imperial College Press, London, 2008.

[20]- Shahmohamadi, H., Mohammadpour, M., Rahmani, R., Rahnejat, H., Garner, C.P. and Howell-Smith, S., "On the boundary conditions in multiphase flow through the piston ring-cylinder liner conjunction", Tribology International, 2015, 90: 164-174.

[21]- Bewsher, S.R., Turnbull, R., Mohammadpour, M., Rahmani, R., Rahnejat, H., Offner, G. and Knaus, O., "Effect of cylinder de-activation on the tribological performance of compression ring conjunction", Proc. IMechE, Part J: J. Engineering Tribology, 2016, 231 (8), pp.997-1006.

[22]- Dowson, D. and Higginson, G.R., "Elasto-hydrodynamic lubrication", 2nd SI edition, Pergamon Press, Oxford, 1977.

[23]- Mufti, R.A., Priest, M. and Chittenden, R.J., "Analysis of piston assembly friction using the indicated mean effective pressure experimental method to validate mathematical models", Proc IMechE, Part D: J. Automobile Engineering 2008, 222, pp. 1441-1457.

[24]- Roelands, C.J., "Correlation aspects of the viscosity-temperaturepressure relationships of lubricating oils", PhD thesis, Delft University of Technology, Netherlands; 1966.

[25]- Houpert, L., "New results of traction force calculations in elastohydrodynamic contacts", Trans. ASME, J. Tribology, 1985, 107, pp. 241248. 
[26]- Mishra, P.C., Balakrishnan, S. and Rahnejat, H., "Tribology of compression ring-to-cylinder contact at reversal", Proc. IMechE, Part J: J. Engineering Tribology, 2008, 222(7), pp. 815-826.

[27]- Tian, T., "Dynamic behaviours of piston rings and their practical impact. Part 1: ring flutter and ring collapse and their effects on gas flow and oil transport", Proc. IMechE, Part J: J. Engineering Tribology, 2002, 216(4), pp. 209-228.

[28]- Baker, C., Theodossiades, S., Rahmani, R., Rahnejat, H. and Fitzsimons, B., "On the Transient Three-Dimensional Tribodynamics of Internal Combustion Engine Top Compression Ring", J. Engineering for Gas Turbines and Power, 2017, 139(6), paper 062801.

[29]- Swift, H.W., "The stability of lubricating films in journal bearings", Proc. Inst. Civil Eng., 1932, 233, pp. 267-288.

[30]- Steiber, W., "Das-Schwimmlager: Hydrodynamische Theorie des Gleitlagers“, VDI-Verlag, Berlin, 1933.

[31]- Arcoumanis, C., Duszynski, M., Flora, H., and Ostovar, P., "Development of a Piston-Ring Lubrication Test-Rig and Investigation of Boundary Conditions for Modelling Lubricant Film Properties", SAE Technical Paper 952468, 1995.

[32]- Styles, G., Rahmani, R., Rahnejat, H. and Fitzsimons, B., "In-cycle and life-time friction transience in piston ring-liner conjunction under mixed regime of lubrication", Int. J. Engine Research, 2014, 15(7), pp. 862-876.

[33]- Chong W.W.F. and Rahnejat, H., "Nanoscale friction as a function of activation energies", Surface Topography: Metrology and Properties, 2015, 3(4): 044002.

[34]- Buenviaje, C.K., Ge, S.R., Rafailovich, M.H. and Overney, R.M., "Atomic force microscopy calibration methods for lateral force, elasticity, and viscosity", In MRS Proceedings, Cambridge University Press, 1998, 522: 187.

[35]- Ahimou, F., Semens, M.J., Novak, P.J. and Haugstad, G., "Biofilm cohesiveness measurements using a novel atomic force microscopy methodology", Appl Environ Microb., 2007; 73(9), pp. 2897-2904.

[36]-

[37]- Taylor, L.J. and Spikes, H.A., "Friction-enhancing properties of ZDDP antiwear additive: part I-friction and morphology of ZDDP reaction films", Tribology Transactions, 2003, 46(3), pp. 303-309. 
[38]- Morina, A. and Neville, A., "Understanding the composition and low friction tribofilm formation/removal in boundary lubrication", Tribology International, 2007, 40(10), pp. 1696-1704.

[39]- Gore, M., Theaker, M., Howell-Smith, S., Rahnejat, H. and King, P., "Direct measurement of piston friction of internal-combustion engines using the floating-liner principle", Proc. IMechE, Part D: J. Automobile Engineering; 2014, 228 (3), pp. 334-354. 